\title{
EDITORIAL
}

\section{SON NECESARIOS CAMBIOS SUSTANTIVOS}

\author{
Jorge Riechmann \\ Profesor titular de filosofía moral (Universidad de Barcelona) \\ Director (en funciones) de la Unidad Técnica del Observatorio de la Sostenibilidad en España
}

1

El 28 de julio de 2004 murió el periodista y escritor Tiziano Terziani, con 65 años de edad. Un par de años antes se habían publicado en castellano sus Cartas contra la guerra, un libro lleno de sabiduría gandhiana y de tensión moral, donde podemos leer ${ }^{1}$ :

«El mundo ha cambiado, debemos cambiar nosotros. Ante todo dejando de fingir que todo es como antes, que podemos seguir viviendo cobardemente una vida normal. Con lo que está sucediendo en el mundo nuestra vida no puede, no debe ser normal. Deberíamos avergonzarnos de esta normalidad».

Todo en nosotros debería sublevarse ante la sugerencia de que vivimos en una situación «normal». La gente construye sus casas sobre la falda del volcán, y a partir del segundo año lo han olvidado ya... Es muy humano, demasiado humano, pero al mismo tiempo resulta inaceptable.

Pocas semanas después de la muerte de Terziani teníamos el barril de petróleo a más de cuarenta y cinco dólares, y todas las sire- nas de alarma aullaban al unísono en la ciudad alegre y confiada... ¡Inflación, desempleo, estancamiento, crisis! El dedo acusador señalaba hacia las torpezas más o menos criminales - la criminal guerra de Irak, el acoso torpe de Putin contra la petrolera Yukos-, pero sobre todo hacia las «causas estructurales»: ¡el consumo en China y la India sube a medida que sustituyen algunas de sus bicicletas por automóviles! Es decir, a medida que hacen precisamente lo que nosotros -los especialistas en «desarrollo»- les hemos dicho que hay que hacer.

Va acercándose el momento de decidir. No hay en este planeta espacio ambiental ni bienes ecológicos suficientes para que algunos cientos de millones de consumidores más se incorporen a nuestro «modelo de desarrollo»: éste es excluyente por definición (aunque nos hemos venido negando con obstinación a reconocer esta verdad palmaria). Ahora, una de dos: o cambiar este modelo $-\mathrm{y}$ entonces hace falta trabajar, producir y consumir de otra manera-, o desplegar y perfeccionar las estructuras de poder fascistas que in nuce ya existen, de manera que la raza de los señores domine sobre las razas de los esclavos dentro de un mundo congelado en desigualdades atroces. Tertium non datur. 
Si eficacia, rendimiento y competitividad son los valores supremos a los que todo lo demás ha de subordinarse, entonces el ser humano ha perdido definitivamente la partida, y lo único que cabría hacer sería buscar un escondrijo para intentar escapar del verdugo. Pero en ningún lugar está escrito que ése sea nuestro destino ineluctable.

\section{3}

Recientemente, varios informes sobre la situación medioambiental de España, que en conjunto trazan un panorama bastante profundo de la misma, han vuelto a lanzar una alarma y a solicitar reflexión y acción de la sociedad española. Se trata del Análisis de los resultados medioambientales de España de la $\mathrm{OCDE}^{2}$; el estudio sociológico El dilema de la supervivencia: los españoles ante el medio ambiente de Juan Díez Nicolás ${ }^{3}$, el informe basado en indicadores Perfil ambiental de España 2004 elaborado por el Ministerio de Medio Ambiente ${ }^{4}$, o Una mirada a nuestro medio ambiente, número monográfico de El Ecologista que conmemora los 25 años de existencia de la revista ${ }^{5}$.

A pesar de la variedad de puntos de vista y presupuestos teóricos en estos trabajos, en todos ellos resuena una advertencia clara: pese a algunas mejoras parciales, la situación medioambiental de nuestro país sigue deteriorándose, y los españoles y españolas hacemos una contribución cada vez mayor a la degradación ecológica global.

Y donde se precisaría cambio sistémico, el sistema propone muda cosmética. (La imagen puede ser: donde necesitamos cambiar el automóvil privado por una buena combinación de bicicleta y transporte colectivo, se nos sugiere que repintemos el coche, quizá con pintura que tenga algo menos de carga tóxica).

La puesta en práctica de los valores ecológicos $-\mathrm{y}$ pienso principalmente en el respeto por todos los seres vivos, la solidaridad con las generaciones futuras de seres humanos y la conservación de los ecosistemas- exige cambios sustantivos en nuestra manera de trabajar, producir, consumir, viajar, esparcirnos. La sostenibilidad de un sistema (en particular, de la economía española) no tiene demasiado que ver con las mejoras marginales en su eficiencia (lo cual no quiere decir que no tengamos que perseguir con tesón la ecoeficiencia): tiene que ver más bien con su metabolismo básico, con las pautas de intercambio de materia y energía entre el sistema y su entorno.

\section{4}

¿Qué nos hace falta para cambiar hacia un mundo socialmente justo y ecológicamente sostenible? Quizá se trate, sobre todo, de recobrar el sentido de lo excepcional, la intuición de lo extraordinario. Volver a cobrar conciencia de lo milagroso en las obras humanas y lo milagroso en la naturaleza.

La improbable maravilla de que al apretar el interruptor se encienda la luz eléctrica (con todo el laborioso esfuerzo humano y la trabajosa historia humana que hay detrás); y la improbable maravilla de que una veintena de aves acuáticas de distintas especies coexistan con bullicioso júbilo en una marisma (con toda la vasta historia natural y toda la diversa interconexión biológica que hay detrás). En la intersección de esas dos clases de milagros puede florecer el punto de vista, el temple moral y la vida emotiva que posibiliten sociedades humanas sostenibles.

Ahí estamos.

\section{BIBLIOGRAFÍA}

1. Terzani T. Cartas contra la guerra. Barcelona: RBA; 2002. 
2. OCDE. Análisis de los resultados medioambientales. España. Madrid: Ministerio de Medio Ambiente; 2004.

3. Díez Nicolás J. El dilema de la supervivencia. Los españoles ante el medio ambiente. Madrid: Obra Social Caja Madrid; 2004
4. Ministerio de Medio Ambiente Perfil ambiental de España 2004. Informe basado en indicadores. Madrid. Ministerio de Medio Ambiente; 2004.

5. VVAA. Una mirada a nuestro medio ambiente. El ecologista 2004. 